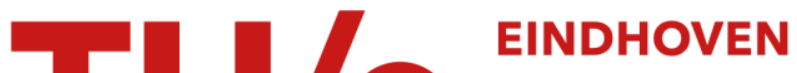 \\ UNIVERSITY OF \\ TECHNOLOGY
}

\section{Dissecting demand response}

\section{Citation for published version (APA):}

Srivastava, A., Van Passel, S., \& Laes, E. (2019). Dissecting demand response: A quantile analysis of flexibility, household attitudes, and demographics. Energy Research and Social Science, 52, 169-180.

https://doi.org/10.1016/j.erss.2019.02.011

\section{Document license: \\ TAVERNE}

DOI:

10.1016/j.erss.2019.02.011

Document status and date:

Published: 01/06/2019

\section{Document Version:}

Publisher's PDF, also known as Version of Record (includes final page, issue and volume numbers)

\section{Please check the document version of this publication:}

- A submitted manuscript is the version of the article upon submission and before peer-review. There can be important differences between the submitted version and the official published version of record. People interested in the research are advised to contact the author for the final version of the publication, or visit the $\mathrm{DOI}$ to the publisher's website.

- The final author version and the galley proof are versions of the publication after peer review.

- The final published version features the final layout of the paper including the volume, issue and page numbers.

Link to publication

\section{General rights}

Copyright and moral rights for the publications made accessible in the public portal are retained by the authors and/or other copyright owners and it is a condition of accessing publications that users recognise and abide by the legal requirements associated with these rights.

- Users may download and print one copy of any publication from the public portal for the purpose of private study or research.

- You may not further distribute the material or use it for any profit-making activity or commercial gain

- You may freely distribute the URL identifying the publication in the public portal.

If the publication is distributed under the terms of Article 25fa of the Dutch Copyright Act, indicated by the "Taverne" license above, please follow below link for the End User Agreement:

www.tue.nl/taverne

Take down policy

If you believe that this document breaches copyright please contact us at:

openaccess@tue.nl

providing details and we will investigate your claim. 
Original research article

\title{
Dissecting demand response: A quantile analysis of flexibility, household attitudes, and demographics
}

\author{
Aman Srivastava $^{\mathrm{a}, \mathrm{b}, *}$, Steven Van Passel ${ }^{\mathrm{a}, \mathrm{c}}$, Erik Laes ${ }^{\mathrm{b}}$ \\ ${ }^{\text {a }}$ Faculty of Applied Economics, University of Antwerp, Prinsstraat 13, Antwerp, Belgium \\ ${ }^{\mathrm{b}}$ Smart Energy \& Built Environment Unit, VITO-Energyville, Thor Park, Poort Genk, 8310, Belgium \\ ${ }^{\mathrm{c}}$ Faculty of Business Economics, Hasselt University, Martelarenlaan 42, Hasselt, Belgium
}

\section{A R T I C L E I N F O}

\section{Keywords:}

Demand response

Demand side management

Electricity

Household energy

User acceptance

Quantile regression

\begin{abstract}
A B S T R A C T
Demand response (DR) can aid with grid integration of renewables, ensuring security of supply, and reducing generation costs. However, not enough is known about how residential customers' perceptions of DR shape their response to such programs. This paper offers a deeper understanding of - and reveals the heterogeneity in - this relationship by conducting a quantile regression analysis of a Belgian DR trial, combining data on response with information on household attitudes towards smart appliances. Results overall suggest that improving response requires subtle shifts in electricity consumption behaviour, which can be achieved through changes in user perceptions. Specifically, if customers are inclined to be flexible, a stronger perception of smart appliances as being beneficial can greatly improve response. With those who are less flexible, the cost of smart appliances is a bigger concern. Thus, when designing DR programs, policymakers should aim to promote modest behaviour changes - so as to minimise inconvenience - in customers, by improving awareness on the benefits of smart appliances. Uptake of such DR programs may be improved by explaining the financial benefits or offering incentives to less flexible population segments. Lastly, improving response among older population segments will require a deeper investigation into their concerns.
\end{abstract}

\section{Introduction}

\subsection{Demand response}

The electricity sector is faced with two medium- to long-term challenges. First, it is a significant contributor to climate change, with nearly $30 \%$ of total greenhouse gas emissions coming from global electricity production [1]. At the same time, electricity consumption trends - coupled with an aging infrastructure - present a challenge for energy security. In Europe, various operating reserves ${ }^{1}$ exist to secure the supply of electricity. The primary reserve is used to maintain load frequency and avoid grid instability, the secondary reserve is used to alleviate imbalances, and the tertiary reserve is used to cope with significant imbalances and major congestion problems [2,3]. In its primary reserve alone, the interconnected European electricity market needs around 3 gigawatts (GW) of capacity [4].
The increasing share of renewable sources in electricity generation is a potential long-term solution for both, mitigating climate change and securing energy supplies. However, the generation of renewable electricity is intermittent in nature, while non-intermittent generation is expensive and storage technologies are still inefficient. Demand response (DR) programs are seen as a promising option for the integration of renewables [5], and as a cheaper alternative to the conventional generation that is currently used to ensure the security of energy supply [4].

DR programs aim to modify the demand patterns for electricity by encouraging its use during peak generation and discouraging its use at times when the load on the grid is highest. This modification of demand is typically achieved through the dynamic pricing of electricity based on the time of its use, or through the external control of appliance loads [6].

The European Commission (EC) estimates a total response potential of $160 \mathrm{GW}$ by 2030 , with $40 \%$ of the potential for peak load reductions

\footnotetext{
Abbreviations: AIC, Akaike information criterion; DR, demand response; DSM, demand side management; EC, European Commission; GW, gigawatt; ICT, in-

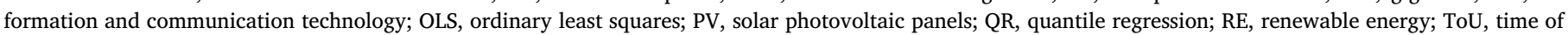
use pricing

* Corresponding author at: Department of Engineering Management, Room B-106, Faculty of Applied Economics, University of Antwerp, Prinsstraat 13, Antwerp, 2000, Belgium.

E-mail addresses: Aman.Srivastava@UAntwerpen.be (A. Srivastava), Steven.VanPassel@UAntwerpen.be (S. Van Passel), Erik.Laes@VITO.be (E. Laes).

${ }^{1}$ An operating reserve is the reserve generating capacity available to the system operator, to meet demand in a short period of time, in case there is a sudden disruption to the power supply or an extensive blackout.
} 
coming from the residential sector [7]. It has thus unveiled a 'Clean Energy for All Europeans' proposal [8] which recommends greater customer access to dynamic pricing contracts, DR programs, smart metering systems, and information feedback. In line with this, DR is being promoted through enabling policy frameworks in many European countries, and DR programs are being increasingly tested and implemented in the residential sector ${ }^{2}$ [11].

Residential DR programs can however be more challenging to implement successfully, due to the limited price responsiveness of households [12]. There have consequently been a number of studies aimed at better understanding household response to - including user perceptions of and concerns with - DR programs.

\subsection{Literature on household response to $D R$}

Often, literature looks at response to DR from varying perspectives. On pricing, for instance, Bartusch et al. [13] found, relying on semistructured interviews and sample statistics, that households do indeed act on price signals by decreasing demand in peak periods and shifting electricity use off-peak periods. From the perspective of information, Hall et al. [14] used focus groups to identify that households want more information to understand the potential benefits of DR. Regarding privacy concerns, Muratori et al.'s [15] review found that consumers are reluctant to allow external control of their appliances, and continue to have concerns about information sharing. Darby and McKenna's [16] review, similarly, points to the need for customer education and attention to data privacy and security. Parag and Butbul [17] found that prospective adopters value the perceived benefits of comfort and convenience over the risks associated with smart home technologies.

Other studies have studied response from multiple perspectives in combination. An EC report found that consumer acceptance of smart appliances depends on the respective device; for instance, smart operation for washing machines and dishwashers is highly accepted. But key user concerns continue to include doubts about the safety of smart appliances, doubts about the maturity of the technology, and the fear of losing control over the operations of such appliances [18]. Brent et al. [19] state that price changes lead to greater conservation effects than moral and social arguments, that knowledge of consumption can maximise the effectiveness of time-varying pricing, and that enabling technology increases the effectiveness of such pricing. Consumer behaviour studies under the US government's Smart Grid Investment Grant program found that enrolment under opt-out approaches was higher than under opt-in approaches due to status-quo effects, and that higher price ratios led to greater response [20]. Kessels et al. [21] reviewed literature and smart grid projects to conclude that dynamic pricing schemes should be simple to understand, with timely notifications of price changes, a considerable potential effect on the energy bill, and automated control.

Existing research has also occasionally thrown up conflicting findings. For instance, Gyamfi et al. [12] stated that a high fraction of households - particularly the richer ones ${ }^{3}$ - did not respond to price signals. However, the Irish Commission for Energy Regulation [24] found that time-of-use (ToU) tariffs do reduce electricity usage, and that higher-consuming households tended to deliver greater reductions. Muratori et al. [15] found that shifting consumption may lead to steeper rebound peaks, while Cosmo and O'Hora [25], using differencein-difference estimates, found that reductions lasted beyond the peak period and that post-peak spikes in usage were not observed. Overall, Parrish et al. [26] find through a systematic review that customer

\footnotetext{
${ }^{2}$ A list of European smart grid projects is available with the EC's Joint Research Center [9], while a list of demonstration projects supported by the US government is available at the US Department of Energy [10].

${ }^{3}$ Richer households tend to consume greater amounts of electricity, as determined by for instance Vesterberg [22] and Silva et al. [23].
}

responses can vary considerably for many reasons and that DR modeling can yield more optimistic results than actual trials, while Srivastava et al. [27] note that response is also dependent on contextual factors.

In this context, Gyamfi et al. [12] suggest greater use of economic behaviour-based approaches to overcome some of the challenges to achieving effective voluntary demand reductions.

\subsection{Scope of current study}

A greater understanding of how user perceptions affect response is needed, in order to better design and implement DR programs in the future. This paper undertakes such an analysis, using a unique approach, by conducting an in-depth study of the heterogenous relationship between user perceptions - taking into account their attitudes towards factors such as information, privacy, control - and response. In this, it focuses on the Belgian region of Flanders.

In addition to the European reserves, Belgium requires 600 megawatts (MW) in its strategic reserve, introduced to cover structural shortages in generation during the winter periods [28,29]. Separately, new legislation in Belgium is establishing the right for an independent aggregator to access consumers directly - this will help to provide an equal footing for all market actors; a good sign for the uptake of DR [11]. In recognition of these market changes at the national and European levels, Belgium has also hosted various smart grid projects [9], largely international and/or R\&D undertakings. Among these, the only domestic DR demonstration - meant to test the feasibility of a broader rollout - was Linear, a smart grid trial in the region of Flanders that concluded in 2014 [30].

This paper analyses the perceptions and behaviours of the households that had participated in the Linear field trial, to see how their attitudes and concerns relate to the flexibility they had offered during this trial. It employs the technique of quantile regressions to disaggregate participant responses to the trial and identify whether different levels of response were associated with different perceptions of and concerns with the project. Such a quantile regression approach has not often been used for electricity consumption analysis. Kaza [31] used a quantile regression analysis to show that while housing size matters for space conditioning, housing type has a more nuanced impact, and that the effects of various factors at the tails of the energy use distribution are substantially different than the average. Khanna et al. [32] conducted a quantile regression analysis of residential electricity consumption in China against socio-economic and demographic factors to study the impacts of demand side management. Romero-Jordan et al. [33] found that in that Spanish context during the recent economic crisis, electricity consumption of medium-high income households was particularly responsive to price increases, whereas that of medium-low income households was more responsive to changes in income.

However, no studies have used this approach to understand demand response from a behavioural perspective and thus guide the direction of the electricity market. By adopting this approach to not only dissect response, but also analyse this response in combination with users' perceptions and attitudes, this paper provides more in-depth recommendations - offering unique perspectives drawn from an actual field trial - to inform a wider demand response rollout in the future.

The contributions of this paper are then threefold: (1) It studies user responses and perceptions of a DR trial in combination; (2) It undertakes a quantitative analysis of this DR trial, where previous studies have tended to study such trials qualitatively; and (3) It applies the method of quantile regressions, for the first time in this field of study, to yield a more comprehensive analysis of the heterogenous relationship between response and perception, by demonstrating how some percentiles of response are more affected by specific attitudes than other percentiles.

This article is set up as follows: Section 2 provides an introduction to the Linear project - from which we obtained our data - and lists the 
Table 1

Linear Test Families.

Source: Adapted from the Linear Consortium [31].

\begin{tabular}{lll}
\hline & Smart Meter & No Smart Meter \\
\hline Smart Appliances & 85 families & 101 families \\
Time-of-use Tariffs & 21 families & 33 families \\
\hline
\end{tabular}

project findings. Section 3 outlines the research method as well as the design for obtaining and processing the data. Section 4 lists the statistical results from our regression analyses, while Section 5 offers an interpretation and discussion of these results. Section 6 concludes with recommendations.

\section{The Linear smart grid trial}

Linear was a demonstration project on smart grid technologies that ran for three years from 2011 until 2014, recruiting participants in three phases between 2011 and 2012, in the Belgian region of Flanders. It aimed to activate residential demand response to facilitate the integration of renewable energy sources in the network. One of the main project objectives was to develop the required technical solutions to realise a breakthrough in DR [34].

The field trial within the project ran for a year; it was based on voluntary participation, and 240 households were involved. The families that participated were already favorably disposed towards smart appliances and were thus not representative of the population. For instance, Linear recruited families that lived in owned houses, rather than rentals and/or apartments. The average participating household had four members, lived in a house built after 1980, and owned at least one television and laptop [34]. The project report [34] states that the incomes of participants were higher than the Belgian monthly per capita of 3445 euros [35], although the actual sample average was not available to the authors.

Despite their positive attitudes, participants were unwilling to run any financial risk in the project, and most households were not willing to replace their existing appliances with smart ones as long as they were still usable. Additional incentives were therefore developed in order to get more users on board. These incentives, such as rebates and free tablets, cannot be reproduced for a full market deployment, which aside from sample representativeness - was acknowledged as a typical limitation that might hinder a successful full-scale rollout [34].

The Linear trial split the participants in two groups (see Table 1); for each group a different reward system was tested. Of the 240 participating families, 54 were exposed to time-of-use electricity pricing they were subject to six rate categories per day, and the prices in these categories were communicated the day before. These 54 were provided with home energy management systems, sub-metering plugs, smart meters, and displays to help them with insights into their consumption.

The primary focus of the trial however was on the remaining 186 families. These families were provided with homes energy management systems and 445 postponable smart appliances - washing machines, dishwashers, and tumble dryers - such that most families had all three appliances ${ }^{4}, 5$; 106 households were also equipped with smart meters. The 186 families received a fee of $€ 1$ per 40 hours of flexibility - defined by Linear as the number of hours within which the appliance had to start after being switched on, in order to finish by the time pre-set by the users - that they offered through these appliances [34].

The trial found that the response to time-based pricing was weak, while the acceptance of smart appliances turned out to be much higher. In total, the participants in the second group offered 200,000 hours of

\footnotetext{
${ }^{4}$ Data on the distribution of these appliances was not available.

${ }^{5}$ A limited number of households also received hot water buffers and electric vehicles; these were not considered in our analysis due to the small sample size.
}

flexibility with their 445 smart appliances, or an average of 450 hours per appliance across the year. Linear extrapolated the results of this field test to estimate that a full DR rollout in Belgium among white good appliances could lead to $280 \mathrm{MW}$ of flexibility being realised [34].

The Linear project also conducted user surveys before and after the one-year field trial, to gauge the acceptance of, and shifts in attitudes with regard to, smart appliances in a residential environment. These surveys were designed based on the technology acceptance model (TAM) that has also been used in other literature [36], and they were designed while minimizing cognitive burden to the respondents. The surveys focused on nine dimensions: (1) perceived safety, (2) perceived maintained control, (3) expected comfort maintenance, (4) perceived expected costs, (5) perceived environmental friendliness, (6) perceived ease of use, (7) perceived usefulness, (8) overall attitude, and (9) intention to use/actual use of smart appliances. The dimension of overall attitude towards smart appliances was also based on survey questions, and was not an aggregate of the other 8 dimensions. Each question in the survey was based on a Likert scale-type response, and mean scores were calculated for each dimension on a scale of 5 .

The 155 responses received by the smart appliance users ${ }^{6}$ showed as seen in Fig. 1 - that participants' attitudes towards smart appliances became slightly less favorable over the course of the trial, across all the dimensions measure. These drops were induced partly due to problems experienced during the field trial; for instance, $55.2 \%$ of the participants experienced poor functionality of the system. However, Linear concluded that the enthusiasm before the start of the field trial shifted to a more nuanced, yet still positive, opinion about the appliances by the end of the trial.

In this way, Linear's analysis provided initial insights into user attitudes regarding the field trial by aggregating the survey responses. This current paper complements and builds upon Linear's findings by disaggregating these responses and coupling them with the results of the trial.

\section{Methods}

\subsection{Research method: quantile regression}

The standard ordinary least squares (OLS) model is commonly used because of its advantages: it is easy to use and analyse, it has wide applicability, and it yields estimates that are unconditional. At the same time however, it has a number of inherent limitations. First, it summarises the response across an entire dataset - thus assuming that one model is appropriate for the whole data - and cannot be customised to noncentral locations, which are often more interesting in a sample distribution than the central locations. Second, the model assumptions are often not realistic; for instance, sample distributions are often not normal and/or homoscedastic. Third, the OLS model can be heavily influenced by the presence of a few outliers in the sample [37].

Conditional quantile modeling, or quantile regression ( $Q R)$, replaces the least squares estimation of OLS with least absolute distance estimation, to estimate the relationships between a response and a set of covariates for specific quantiles (or percentiles) of the response distribution. While the linear regression model specifies the change in the conditional mean of the dependent variable, subject to a change in the covariates, the QR model specifies changes in its conditional quantile where the $50^{\text {th }}$ quantile is the median. Since multiple quantiles can be modeled, it is possible to get a more complete understanding of the response distribution. Further, since outliers can be isolated into the top or bottom quantiles, QR estimates are robust against them [37,38].

\footnotetext{
${ }^{6}$ The results of the surveys are captured in an unpublished user acceptance (UA) report. The authors of this paper were able to access the UA report as well as a limited set of the underlying data, though they were not provided with the underlying methodology for assigning scores to the attitude measurements.
} 


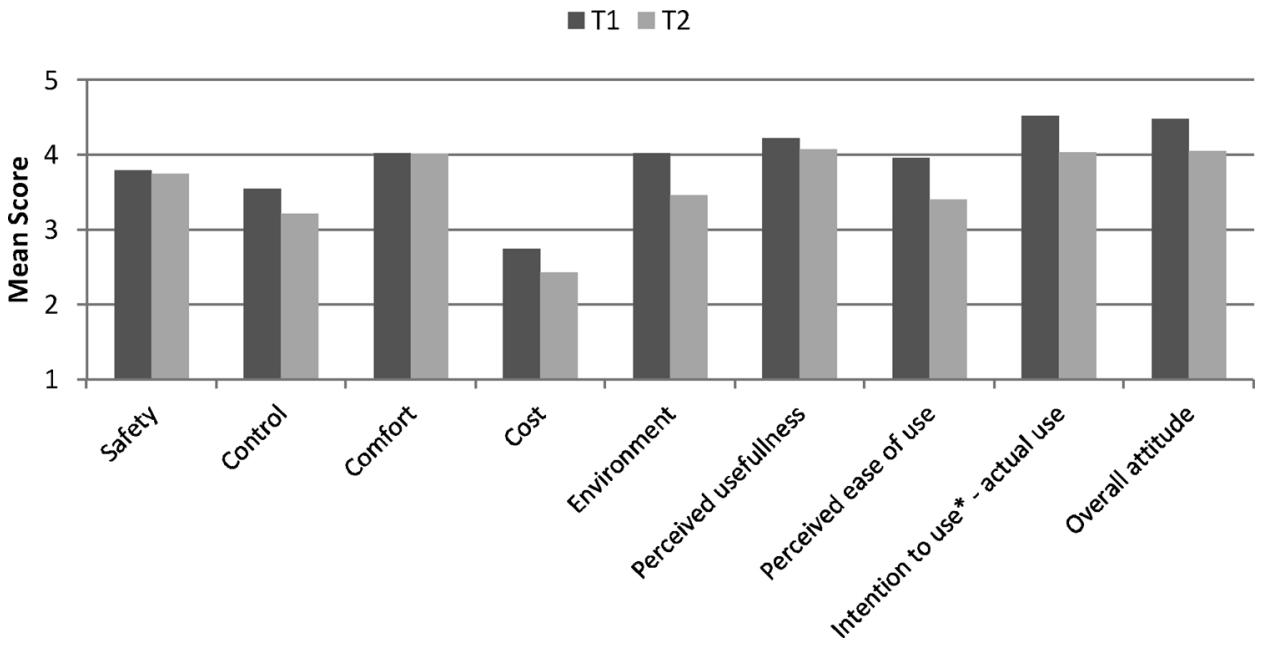

Fig. 1. Mean Scores on Attitude Measurements Before (T1) and After (T2) Trial. Source: Unpublished Linear User Acceptance Report.

The $\mathrm{p}^{\text {th }}$ quantile denotes that value of the response below which the proportion of the sample population is p. Thus, similar to a standard OLS model, which takes the form in Eq. (1), a QR model, for the $\mathrm{p}^{\text {th }}$ quantile, takes the form shown in Eq. (2). Thus in the QR model, the coefficients are quantile-specific.

$\mathrm{y}_{\mathrm{i}}=\beta_{0}+\beta_{1} \mathrm{x}_{1 \mathrm{i}}+\ldots+\beta_{\mathrm{j}} \mathrm{x}_{\mathrm{ji}}+\varepsilon_{\mathrm{i}}$

$\mathrm{y}_{\mathrm{i}}=\beta_{0}^{(\mathrm{p})}+\beta_{1}^{(\mathrm{p})} \mathrm{x}_{1 \mathrm{i}}+\ldots+\beta_{\mathrm{j}}^{(\mathrm{p})} \mathrm{x}_{\mathrm{ji}}+\varepsilon_{\mathrm{i}}^{(\mathrm{p})}$

Where

$y_{i}=$ Response variable for $i^{\text {th }}$ observation

$\beta_{j}=$ Model coefficient for $j^{\text {th }}$ predictor variable

$\mathrm{x}_{\mathrm{ji}}=\mathrm{j}^{\text {th }}$ predictor variable for $\mathrm{i}^{\text {th }}$ observation

$\varepsilon_{\mathrm{i}}=$ Error term for $\mathrm{i}^{\text {th }}$ observation

However, while the OLS coefficients are determined by taking those values of the parameters that minimise the sum of squared residuals, the QR coefficients are determined by taking those values of the parameters that minimise the weighted sum of absolute residuals, as shown in Eq. (3) below. This weighted sum gives asymmetric penalties for overprediction and underprediction, with asymmetry increasing as $\mathrm{p}$ approaches 0 or 1 . It may be noted that the estimation of coefficients for each quantile regression is based on the weighted data of the whole sample, and not just the portion of the sample at that quantile [37].

$\Sigma \quad \mathrm{i}: \mathrm{y} \geq \mathrm{x}^{\prime} \beta(\mathrm{p})\left|\quad \mathrm{y}_{\mathrm{i}}-\beta_{0}^{(\mathrm{p})}-\beta_{1}^{(\mathrm{p})} \mathrm{x}_{\mathrm{i}} \quad \ldots-\beta_{\mathrm{j}}^{(\mathrm{p})} \mathrm{x}_{\mathrm{ji}} \quad\right|+\Sigma \quad$ i: $<<\mathrm{x}^{\prime} \beta(1-\mathrm{p}) \mid$ $\mathrm{y}_{\mathrm{i}}-\beta_{0}^{(\mathrm{p})}-\beta_{1}^{(\mathrm{p})} \mathrm{x}_{\mathrm{i}} \ldots-\beta_{\mathrm{j}}^{(\mathrm{p})} \mathrm{x}_{\mathrm{ji}}$

Unlike OLS, the QR coefficients do not have a closed-form solution, and Eq. (3) is instead solved using linear optimisation algorithms, such as the simplex method. However, the quantile regression estimator is asymptotically normally distributed [37].

\subsection{Research design: data and pre-processing}

The underlying data from the Linear field trial was provided by VITO, the Flemish Institute for Technological Research. This data included, for each participating household, (1) demographics for the head of the family age and gender, (2) participation details, such as whether the participants were given smart appliances or on ToU tariffs, (3) responses to the pre-trial and post-trial attitude surveys, and (4) responses to the field trial, in terms of hours of flexibility and bonuses awarded. However, much other data from the trial, particularly about the sample constituents, was not disclosed to us for confidentiality reasons.

The authors processed this data as follows: (1) translated the data from Flemish Dutch into English; (2) compiled and cross-referenced the data from across various databases provided by VITO; (3) filtered out questions that were open-ended, rather than numerical, scaled, or binary in response; (4) removed questions that were unrelated to user behaviour or response; and (5) coded the responses to enable statistical analysis.

The analysis was conducted in the statistical software R. Since the focus of the Linear trial was on smart appliance users - the sample of users on ToU tariffs is smaller, and the response to smart appliances turned out to be stronger in the field trial - this analysis also focuses on the same group, and the sample thus consisted of the 155 smart appliances users who had completed Linear's user surveys. The total hours of flexibility offered by each household across the duration of the trial was assigned as the response variable. ${ }^{7}$

Existing literature - such as the studies featured in Section 1.2 suggests that household response to, and even willingness to participate in, DR programs is related to factors such as pricing considerations, awareness of the benefits of DR, presence of information feedback systems such as smart meters or in-home usage displays, privacy concerns relating to smart appliances and meters, confidence in the associated technologies, impacts on convenience relating to the operability of appliances, and respondents' psychological profiles, such as their attitudes towards the environment and preferences for loss and/or risk aversion. Based on the literature, the analysis for this paper hypothesized response to be a generalized function of the following:

Response $=\mathrm{f}$ (Pricing, Knowledge, Feedback, Privacy, Technology, Convenience, Respondent profile)

The response variable was thus regressed on various combinations of 40 predictors, which are listed in Appendix A. These predictors included available demographic details, and also the scale-based responses to questions in the attitude surveys that broadly gauged environmental attitudes, financial considerations, perceptions of inconvenience, information needs, privacy concerns, attitudes towards technology, and perceptions of actual response and behaviour change.

The analysis included both OLS and QR models in order to gauge overall model fit as well as explore the differences in results between the two approaches. Responses to the scale-based questions were treated as categorical variables, and their 5 responses levels were coded into 4 dummy variables, capturing the responses from "No" (Level [2])

\footnotetext{
${ }^{7}$ Flexibility was calculated within the Linear trial as the number of hours within which the appliance had to start after being switched on, in order to finish by the time set by the users, i.e. the programmable delay. While users could switch on their appliances at any time, independent of peak or off-peak periods of consumption, the maximum programmable delay in any use cycle was 24 hours.
} 


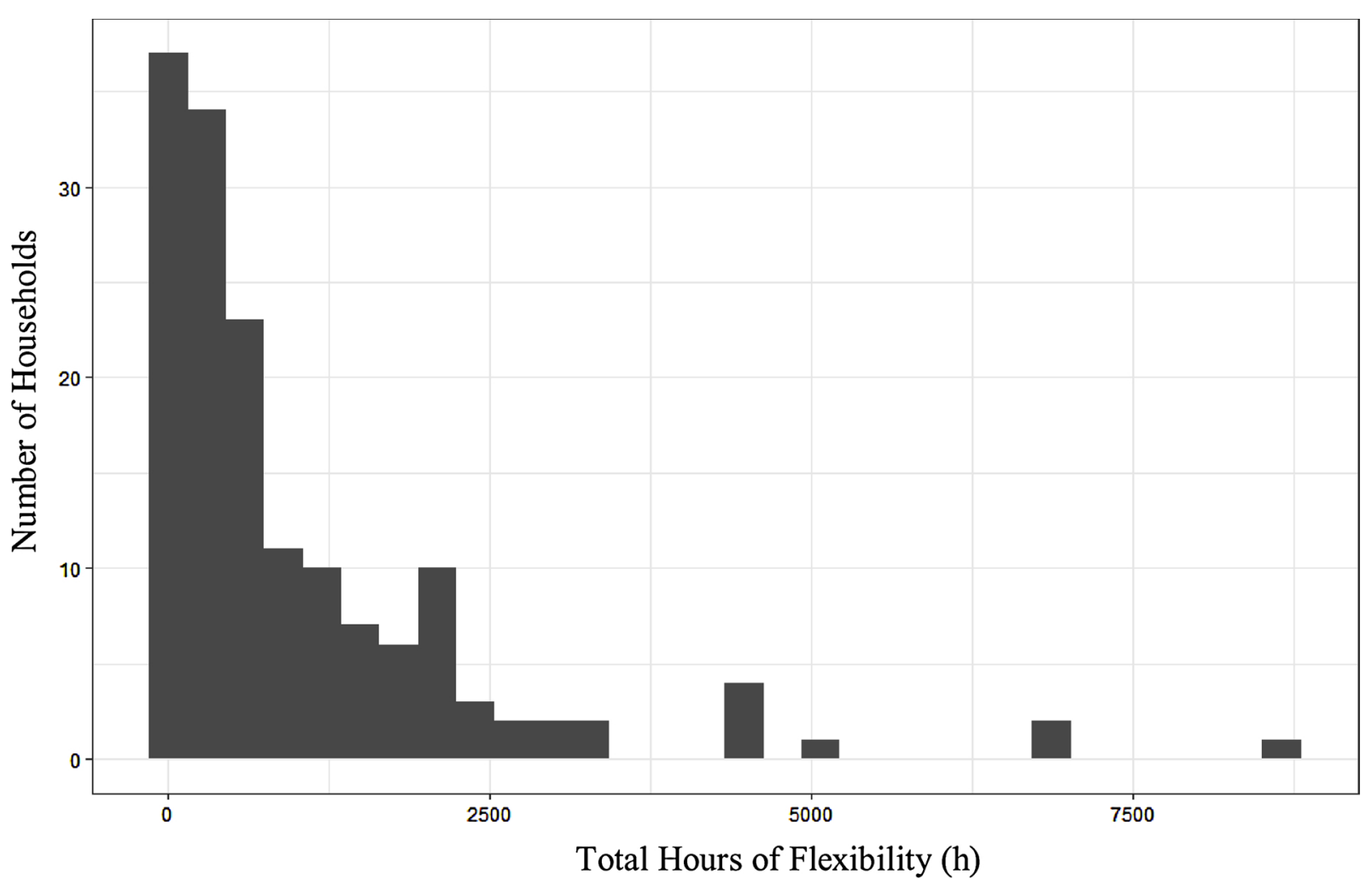

Fig. 2. Histogram of Total Hours of Flexibility per Household across the Trial.

to "Completely" (Level [5]). The coefficients for these four categories are relative to the responses at the first level ("Not at all").

\section{Results}

Fig. 2 illustrates the distribution of the response variable, i.e. the total flexibility per household across appliances through the year. It is seen that the distribution is skewed to the right with a long tail. The gaps in distribution highlight the existence of outliers in the sample, which are likely to bias OLS results. This indicates that quantile regression can yield more accurate insights about the trial than traditional center-weighted statistics.

Following the steps detailed in Section 3, the predictors listed in Table 2 were together found to have the best fit for both the OLS and QR models, out of the 40 predictor variables tested.

The hypothesized relationship between response and the respondent details/attitudes that was detailed in Eq. (4) is thus regression-validated, and its quantile-dependent form is summarised as:

Flexibility $=$

$\beta_{0}^{(\mathrm{p})}+\beta_{1}^{(\mathrm{p})}($ Age $)+\beta_{2}^{(\mathrm{p})}($ SA_NBenefits $)+\beta_{3}^{(\mathrm{p})}$ (SA_Efficient $)+\beta_{4}^{(\mathrm{p})}$ (Use-

d_SA) $+\beta_{5}^{(\text {p) }}$ (Buy_wSubsidies)

$+\beta_{6}^{(p)}($ Buy_wRemote $)+\beta_{7}^{(\text {(p) }}($ Behaviour $)+\varepsilon$
Table 3 provides some initial descriptive statistics for the two continuous variables in the model - the hours of flexibility that serves as the response variable, and the respondents' ages - as well as the response distributions for the six categorical predictor variables that were drawn from the survey.

The mean hours of flexibility offered by the smart appliance users across appliance per household - were 1015 while the median value was 522. These numbers complement Fig. 1 in suggesting that the response distribution is skewed to the right with a long tail, as also evidenced by the high coefficient of skewness, of 2.70 .

The average age of the users was distributed normally, with the mean and median being nearly equal in value at 47 years. The youngest user was 28 years old while the oldest was 71 , resulting in a range of 43 years across the sample.

Among the categorical variables, in most cases, users were generally in agreement with the questions asked, with few respondents falling in the first two response categories. This distribution suggests a few points regarding user perceptions. First, most users did not feel that using these appliances had offered any significant benefits to them. Conversely, users were neutral or generally agreed that using smart appliances increased their efficiency. Most participants agreed that they made use of their smart appliances, although their responses to the last question suggest that they didn't strongly feel like their behaviour had

Table 2

Predictor Variables in Final Model.

\begin{tabular}{|c|c|c|c|c|}
\hline \# & Question & Type & Levels & Notation \\
\hline 1. & Respondent age & Continuous & - & Age \\
\hline 2. & To what extent do you agree with the statement, 'The use of smart appliances did not seem to benefit me' & Categorical & 5 & SA_NBenefits \\
\hline 3. & To what extent do you agree with the statement, 'The use of smart appliances made me work more efficiently' & Categorical & 5 & SA_Efficient \\
\hline 4. & To what extent do you agree with the statement, 'I made use of my smart appliances' & Categorical & 5 & Used_SA \\
\hline 5. & Would subsidies play a role in deciding to buy smart appliances or an energy management system & Categorical & 5 & Buy_wSubsidies \\
\hline 6. & Would the ability to operate appliances remotely play a role in deciding to buy smart appliances or an energy management system & Categorical & 5 & Buy_wRemote \\
\hline 7. & To what extent do you agree with the statement, 'Our behaviour changed as the field test progressed' & Categorical & 5 & Behaviour \\
\hline
\end{tabular}


Table 3

Descriptive Statistics and Response Distributions.

\begin{tabular}{|c|c|c|c|c|c|c|}
\hline Continuous Variable & Count & Mean & Std Dev & Median & Range & Skewness \\
\hline Hours of flexibility & 155 & 1015 & 1383 & 522 & 8657 & 2.70 \\
\hline Age & 155 & 47 & 10 & 47 & 43 & 0.41 \\
\hline
\end{tabular}

Categorical Variable

Responses per Category

\begin{tabular}{|c|c|c|c|c|c|}
\hline & \\
\hline & 1: Not at all & 2: No & 3: Neutral & 4: Yes & 5:Completely \\
\hline SA_NBenefits & 3 & 28 & 15 & 65 & 42 \\
\hline SA_Efficient & 8 & 18 & 59 & 51 & 16 \\
\hline Usèd_SA & 0 & 7 & 9 & 79 & 57 \\
\hline Buy_wSubsidies & 3 & 5 & 23 & 71 & 50 \\
\hline Buy_wRemote & 4 & 20 & 26 & 73 & 30 \\
\hline Behaviour & 12 & 41 & 34 & 60 & 7 \\
\hline
\end{tabular}

changed through the course of the field test. However, among participants with smart appliances, most claimed they had changed their behaviour to some extent. Lastly, participants did largely agree that the availability of subsidies, and the ability for them to operate appliances remotely, would influence their decision to buy smart appliances and energy management systems.

The OLS results for this model - regressing total hours of flexibility across the duration of the field test on the seven questions in Table $2-$ are captured in Table 4 below. The R-squared of this model is 0.442 while the adjusted R-squared is 0.333 . Diagnostics for this OLS model are captured in Appendix B and suggest that the data is not normally distributed. Further, a studentized Breusch-Pagan (BP) test ${ }^{8}$ yields a test statistic of 37.765 at 24 degrees of freedom for a p-value of 0.037 , confirming the presence of heteroscedasticity.

Given the nonnormal nature of the distribution and the existence of heteroscedasticity, it is appropriate to further disaggregate and analyse the data, departing from center-weighted averages. We thus conduct a quantile regression analysis at five quantiles, the $10^{\text {th }}, 25^{\text {th }}, 50^{\text {th }}, 75^{\text {th }}$, and $90^{\text {th }}$ - where higher quantiles represent the more flexible segments of the sample - in which we use the bootstrap measure ${ }^{9}$ for standard errors. The results of the quantile regressions are also included in Table 4. The quantile-specific pseudo R-squared [40] indicates that the model is a good fit, and that it is better at explaining higher quantiles. The accompanying Akaike information criterion (AIC) values further indicate that the fit is at least comparable to the OLS model.

It may however be noted that some of the variables were included in this model, even though their quantile coefficients are not statistically significant, because they were significant in the OLS model and because their retention improved the model fit. The trends among these retained coefficients may be validated through future research on larger samples. It is also mentioned that in any regression with categorical variables of ' $n$ ' levels, the coefficients of the remaining (n-1) levels are estimated relative to the first level - for this reason, the table below shows coefficients for only the remaining four levels of each categorical variable. ${ }^{10}$

\footnotetext{
${ }^{8}$ The studentized BP test uses different test statistics from the original BP test. If $\xi *$ is the studentized test statistic and $\xi^{\wedge}$ be the original one, then $\xi^{\wedge}=\lambda \xi *$, where $\lambda=\operatorname{Var}\left(\varepsilon^{2}\right) / 2 \operatorname{Var}(\varepsilon)^{2}$. The asymptotic power of the original BP test is sensitive to the kurtosis of the distribution of $\varepsilon$, and the significance levels of the test are correct only in the special case of Gaussian kurtosis. Thus, the studentized BP test is more robust than the original one [39].

${ }^{9}$ The bootstrap method uses Monte Carlo simulations to do a repeated random sampling with replacement within the sample. Bootstrapping is asymptotically more accurate than the standard intervals obtained using sample variance and assumptions of normality. It is better for smaller sample sizes, and is preferable in general because it makes no assumptions about the distribution of response [37].

${ }^{10}$ The variable "Used_SA", discussed in Section 4 below, was categorised with 4 levels, because it had no responses in the first level ("Not at all"). Its coefficients are relative to responses at the second level ("No").
}

Figs. 3-5 show the coefficients - on the y-axis - of three different predictors (SA_NBenefits, Buy_wSubsidies, Behaviour) across their quantiles, along the $\mathrm{x}$-axis. In these figures, the black lines indicate the quantile coefficients, with the dots signifying the actual quantiles measured, and the dotted horizontal red lines denote the constant OLS coefficients. The figures are meant to visually highlight the divergences in the quantile coefficients from their OLS counterparts.

The statement 'The use of smart appliances did not seem to benefit me' has large and negative coefficients in each category and quantile. The coefficients increase from the $10^{\text {th }}$ to the $25^{\text {th }}$ quantile, but then follow a downward trend in general - they typically start higher than the OLS coefficients but end up lower among the more responsive participants. The higher categories (categories 4 and 5) are less negative at lower quantiles and more negative at higher quantiles, which possibly indicates a greater variation in flexibility at these levels.

The question 'Would subsidies play a role in deciding to buy smart appliances or an energy management system?' has more respondents in the higher response categories. In general, these higher response categories have lower coefficients than the lower response categories. Additionally, the coefficients increase substantially from the lower to the higher quantiles, and are consistently different from the OLS coefficients.

The bulk of responses to the statement 'Our behaviour changed as the field test progressed' fall in the middle three categories. While the coefficients of these three categories are similar at the $10^{\text {th }}$ quantile, only those for category 2 ("No") fall consistently as the quantiles increase, becoming negative at the 90th quantile. For the 3rd and 4th categories ("Neutral" and "Yes"), the coefficients fall until the median mark and then rise. In general though, they stay below the OLS coefficients, suggesting that outliers may have significantly influenced the OLS model in this case.

\section{Discussion}

The Linear trial was set up in a way that roughly approximated the recommendations from existing literature on DR design: it used appropriate appliances such as washing machines and dishwashers [18]; it provided enabling technologies such as smart meters and tablets [19]; and it enrolled participants using an opt-out approach [20]. Given this, the results broadly show that maximizing the response to residential DR programs would indeed require inducing changes in behaviour - in different ways - among different households. These changes in behaviour are closely linked with user perceptions of the benefits of smart appliances, and with considerations of convenience and cost. Further, age will be likely to affect flexibility and response and must thus be factored in as well.

The results of both the OLS and the quantile regressions - for those predictor variables which had significant coefficients - are discussed in greater detail listwise below. 
Table 4

OLS and Quantile Coefficients, with Goodness-of-fit Statistics ${ }^{\mathrm{a}}$

\begin{tabular}{|c|c|c|c|c|c|c|}
\hline Variable & OLS coefficients & 10th Q coeff & 25th Q coeff & 50th Q coeff & 75th Q coeff & 90th Q coeff \\
\hline Intercept & 2209.27 & $2837.58()$. & 3058.07 (.) & 2995.62 & 3198.89 & 2147.49 \\
\hline Age & $-20.13()$. & -3.09 & -5.07 & -7.03 & -21.58 & $-41.41()$. \\
\hline SA_NBenefits - [2] & $-2724.35 * * *$ & -2594.54 * & $-2162.42 *$ & $-2590.55 *$ & $-3127.65 *$ & $-3079.53 *$ \\
\hline SA_NBenefits - [3] & $-2402.60 * *$ & $-2526.51 *$ & $-2350.66 *$ & $-2693.86 *$ & $-2491.74()$. & $-2955.84()$. \\
\hline SA_NBenefits - [4] & $-2793.67 * * *$ & -2529.86 * & $-2204.02 *$ & $-2594.28 *$ & $-3067.76 *$ & $-3438.31 *$ \\
\hline SA_NBenefits - [5] & $-2671.18 * * *$ & -2406.70 * & $-2147.60 *$ & $-2468.95 *$ & $-3143.49 *$ & $-3334.28 *$ \\
\hline SA_Efficient - [2] & -580.58 & -323.12 & -786.42 & -1114.93 & -1001.04 & -89.61 \\
\hline SA_Efficient - [3] & -1027.94 * & -558.02 & -836.73 & -1013.82 & -941.85 & -368.36 \\
\hline SA_Efficient - [4] & -634.96 & -503.29 & -723.88 & -842.32 & -645.77 & 1140.65 \\
\hline SA_Efficient - [5] & -412.54 & -250.89 & -623.94 & -694.22 & -897.70 & 597.98 \\
\hline Used_SA - [2] & - & - & - & - & - & - \\
\hline Used_SA - [3] & 53.09 & -28.85 & -36.42 & 17.10 & 164.87 & -699.24 \\
\hline Used_SA - [4] & 672.40 & 335.19 & 148.63 & 153.48 & 463.49 & -401.72 \\
\hline Used_SA - [5] & $1341.74 *$ & 345.86 & 384.53 & 484.76 & 1572.56 (.) & 1805.17 \\
\hline Buy_wSubsidies - [2] & $2772.37 * *$ & 219.13 & 570.39 & 1879.83 & 2909.01 & $7351.63 *$ \\
\hline Buy_wSubsidies - [3] & 1597.12 (.) & 146.10 & 130.39 & 1186.21 & 2344.99 & 4030.03 (.) \\
\hline Buy_wSubsidies - [4] & 1352.10 & 109.80 & 44.80 & 1179.12 & 2036.38 & 3524.45 \\
\hline Buy_wSubsidies - [5] & 1645.38 (.) & 98.30 & 105.48 & 1326.43 & 2353.88 & 4544.94 * \\
\hline Buy_wRemote - [2] & 564.86 & -278.91 & -106.56 & 440.20 & 980.66 & 1787.64 \\
\hline Buy_wRemote - [3] & 539.20 & -237.32 & 168.53 & -81.78 & -299.72 & 1410.12 \\
\hline Buy_wRemote - [4] & -120.42 & -355.21 & 57.64 & -212.65 & -463.80 & 219.94 \\
\hline Buy_wRemote - [5] & -293.21 & -358.15 & -50.38 & -153.37 & -599.14 & 129.43 \\
\hline Behaviour - $[2]$ & 492.11 & 335.76 & 141.25 & 69.75 & 17.96 & -45.29 \\
\hline Behaviour - [3] & 603.31 & 332.36 & 61.82 & 43.24 & 185.64 & 759.10 \\
\hline Behaviour - [4] & $1015.83 *$ & 307.33 & 30.49 & 11.16 & 345.69 & 444.33 \\
\hline Behaviour - $[5]$ & $1929.46 * *$ & $1378.07 * *$ & $1520.80 * *$ & 1425.85 (.) & 1160.49 & 45.73 \\
\hline Adjusted/Pseudo $\mathrm{R}^{2}$ & 0.333 & 0.194 & 0.227 & 0.278 & 0.364 & 0.454 \\
\hline AIC Values & 2529.573 & 2371.533 & 2397.410 & 2456.699 & 2532.723 & 2609.456 \\
\hline
\end{tabular}

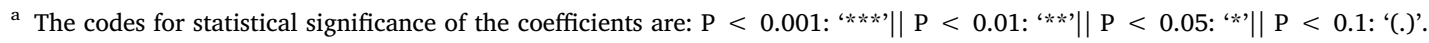

[a] Category 2
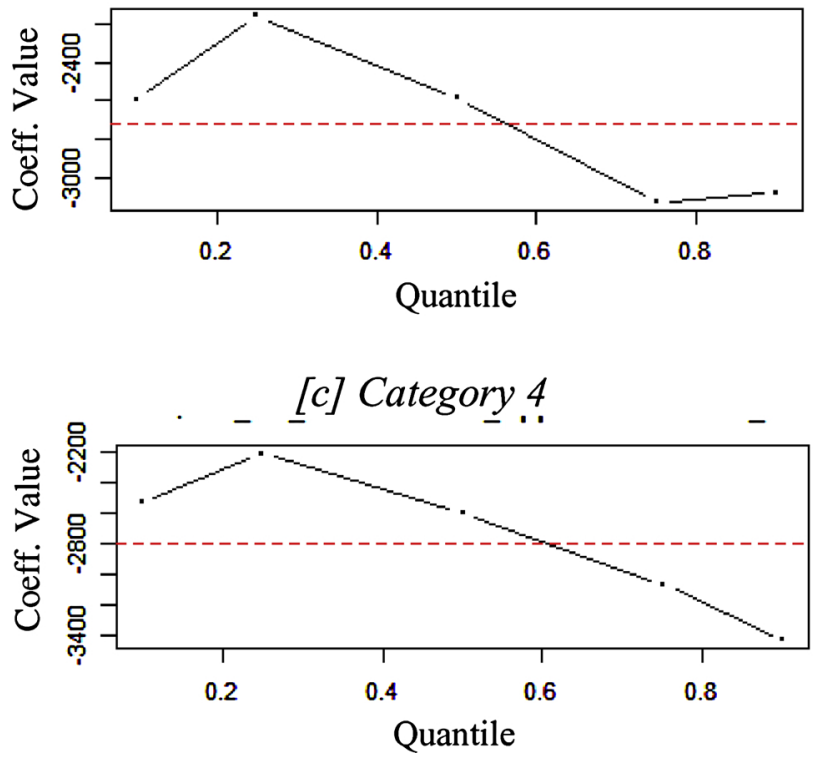

[b] Category 3

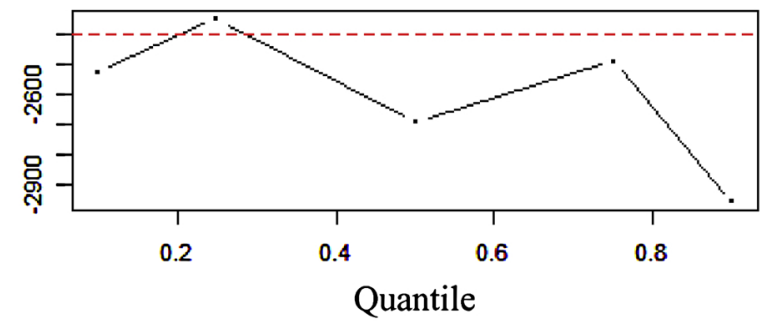

[d] Category 5

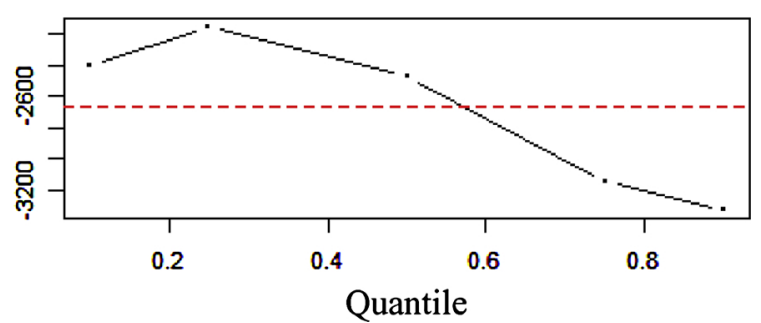

Fig. 3. [a-d]: Plotted OLS and QR Coefficients for Perceived Smart Appliance Benefits (SA_NBenefits) by Quantile.

\subsection{Age}

In the OLS analysis, age has a negative coefficient, suggesting that in general, younger respondents are more likely to offer greater flexibility. This is in line with existing literature - such as Hauk et al's meta-analysis [41] - that states that younger populations tend to be more flexible in general and more comfortable with new technologies.

This result is further interpreted by the quantile analysis, which shows that respondent age doesn't greatly affect response among the least flexible participants, but that there is a large negative relationship between age and flexibility among the highest quantiles. That is, age may not be a great predictor of inflexibility, but being younger does substantially increase response even among the most flexible respondents. For instance, among the least flexible $10 \%$ of users, an increase in age of one year saw a reduction of only $3 \mathrm{~h}$ in total flexibility across the trial, but among the most flexible $10 \%$, an increase in age of one year saw a reduction of $41 \mathrm{~h}$ in total flexibility.

This layering suggests that other concerns play a more significant role among the least responsive, rather than their age, and that a lack of response may therefore not be a function of such demographic variables. 
[a] Category 2

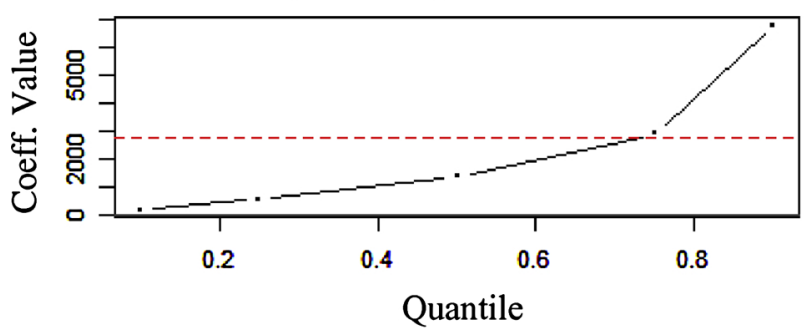

[c] Category 4

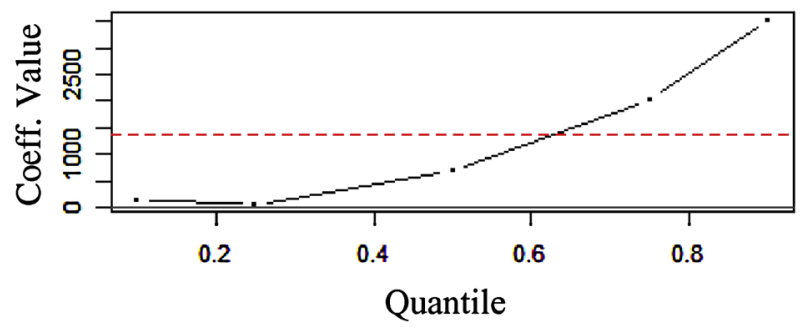

[b] Category 3

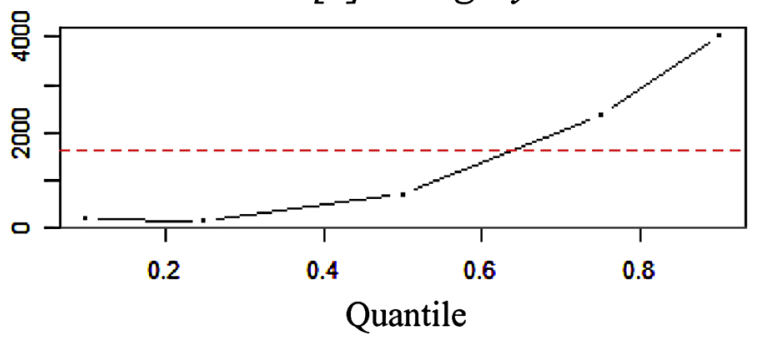

[d] Category 5

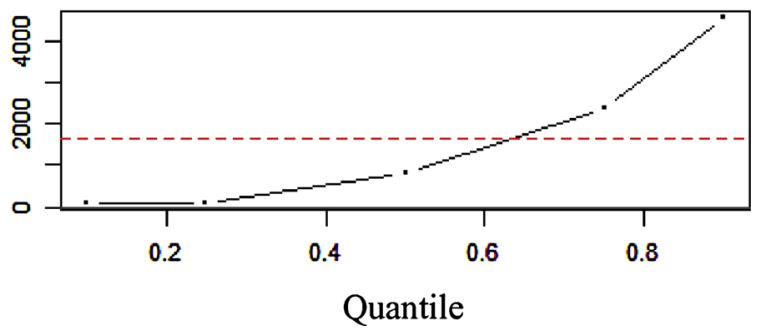

Fig. 4. [a-d]: Plotted OLS and QR Coefficients for Role of Subsidies (Buy_wSubsidies) by Quantile.

[a] Category 2

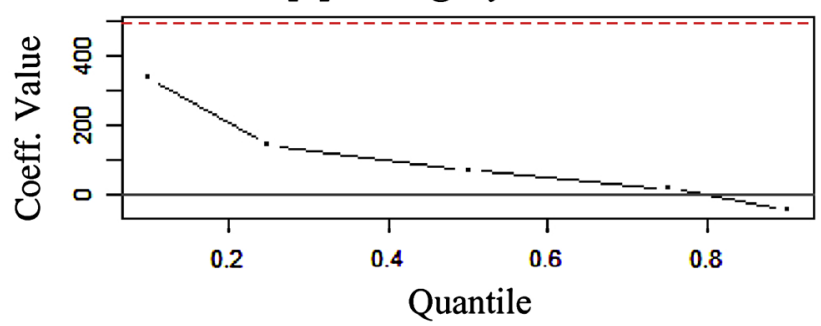

[c] Category 4

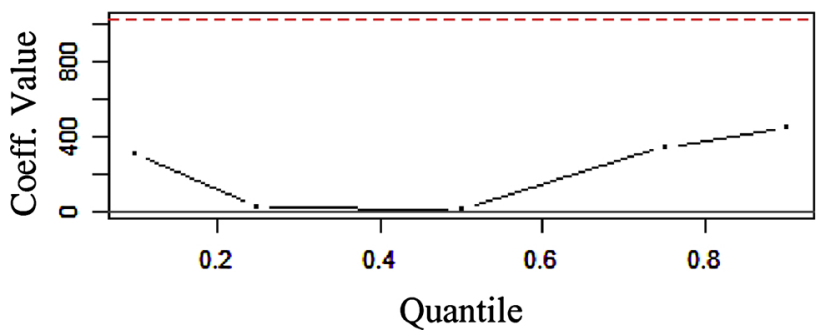

[b] Category 3

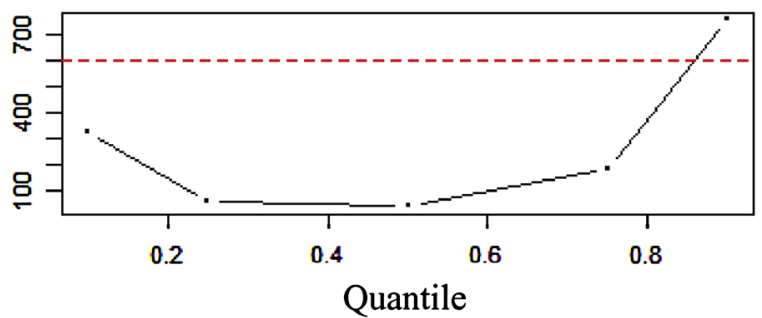

[d] Category 5

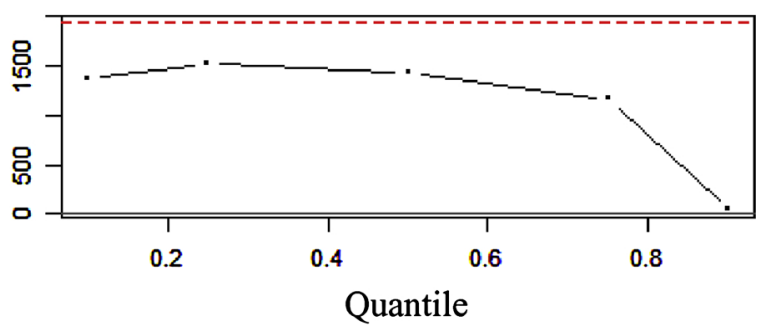

Fig. 5. [a-d]: Plotted OLS and QR Coefficients for Perceived Behavior Change (Behaviour) by Quantile.

\subsection{Perceived benefits from using smart appliances}

Across the sample, participants were much less likely to offer flexibility if they perceived less of a benefit to using smart appliances. This extends existing findings $[14,16]$, by demonstrating that not only do households want to better understand the potential benefits of DR, but that a DR program's success hinges on this understanding.

Looking deeper, we see that at higher quantiles, the coefficients became more negative; i.e. among the participants who offered the greatest flexibility, a negative perception of the benefits of smart appliances tended to reduce flexibility much more than among those that offered the least flexibility.

This result suggests that negative perceptions of the benefits of smart appliances are a big challenge, particularly among those who are otherwise likely to be more responsive to DR. However, it again suggests that population segments that are less likely to be responsive are less influenced by the perceived benefits of smart appliances, and may have other concerns that limit their response.

\subsection{Usage of smart appliances}

Most people claimed to have used their smart appliances at least to some extent, and a greater extent of use was, expectedly, correlated with offering higher flexibility. This corroborates findings from comparable trials, where households that regularly used the smart appliances were more likely to have shifted their electricity usage [42].

Although less clear among the top and bottom deciles of the respondents, the general trend of flexibility being correlated with extent of smart appliance usage was consistent, and the correlation was uniformly stronger at higher quantiles of flexibility.

\subsection{The role of subsidies in deciding to buy smart appliances}

Most respondents generally agreed that subsidies would indeed 
influence their decision to buy smart appliances. This aligns with the findings by Brent et al. [19] and Kessels et al. [21] about the role that financial savings can play on DR implementation.

Respondents who were more influenced by subsidies were also less likely to offer flexibility in general, although the coefficients in the highest quantile of response deviated from this trend. Overall, it can be seen that the coefficients expectedly increase at higher quantiles.

Thus among the least responsive participants, financial considerations were more inversely related with flexibility than among the most responsive. This suggests that - across the factors explored in this paper - price sensitivity is the main concern among less responsive populations.

\subsection{Behaviour changes over the course of the field test}

Respondents did not completely agree that their behaviour had changed over the course of the field test, even though most of them had used their smart appliances. There was however a positive relationship between stated behavior change and actual flexibility revealed.

Among respondents who claimed that their behaviour hadn't changed, greater flexibility (i.e. at higher quantiles) was associated with decreasing coefficients, suggesting that they were less likely to have been among the most flexible. Among respondents who were neutral to somewhat agreeable on the behaviour change, the flexibility tended to decrease towards the middle quantiles and increase rapidly towards the higher quantiles, suggesting that perhaps responses in those categories primarily populated the highest quantiles.

These findings from the Linear DR trial cannot be directly compared with other trials, because most other trials have not combined DR demonstrations with a study of participant attitudes and behaviors. Overall, however, our results strengthen and complement many of the general findings from existing literature, particularly via the OLS model.

The quantile regression analysis further demonstates that these findings are not uniformly applicable even within a limited sample, but are more nuanced, something that previous studies have not done. It reveals additional insights over the OLS model - and over existing literature - and demonstrates the variations in the determinants of flexibility, by showing that response is more affected (1) at the higher percentiles by factors such as age and perceived smart appliance benefits, and (2) at the lower percentiles by factors such as the availability of subsidies.

The remaining factors from the surveys - such as the adequacy of consumption information, the impacts on convenience, and privacy were not found to be significant. This is possibly because of the considered design of the trial, or because the sample consisted of higherincome, pro-environment, early adopters of technology who opted to participate in it.

The results however suggest that different strategies and incentives should be devised, customized to different population segments, in order to maximize the likelihood of success of future demand response programs.

\section{Conclusions and policy implications}

The European interconnected market needs $3 \mathrm{GW}$ in the primary reserves it uses to avoid grid instability. At a national level, Belgium further needs 500-600 MW in its strategic reserve. Demand response can thus play a large role in promoting national and regional energy security, aside from helping with the grid integration of renewables.

Studies on demand response have thus far focused on regulatory updates, consumer access, balancing markets, and wholesale markets. But a key challenge for DR is increasing consumer trust and participation [43]. The Clean Energy package of 2016 does propose access to smart meters and better information, and Belgium in particular is rolling out smart meters nationwide in a phased manner, starting with prosumers. However, no concrete steps have yet been outlined - at the EU or national levels - on how to increase consumer uptake of DR.

This paper analyses a recently-concluded Belgian residential electricity demand response trial, using response data from 155 participating families, coupled with accompanying surveys that were used to gauge these families' attitudes to smart appliances. The objective of combining the two was to understand in detail how demand flexibility is correlated with users' perceptions of and concerns with smart appliances, and to thereby offer specific recommendations to promote consumer participation in DR. The paper relies on the method of quantile regression analysis to dissect user responses and see how these perceptions and concerns vary at different levels of response.

The results showed that there is a clear link between modest changes in user behaviour and the demand flexibility that can be realised. Thus, for future DR programs to be successful, policymakers should target small shifts in behaviour - avoiding the excess changes that might result in user inconvenience - and incorporate these effects into conventional estimates of the economic feasibility of such programs.

Flexibility was also found to be linked to user perceptions of the benefits of smart appliances. It is particularly important that groups that are more likely to be responsive should perceive smart appliances as being beneficial. Thus, in order to induce the aforementioned behavioural changes, DR implementation should be enabled by fully functional technologies and could accompanied by awareness campaigns among such groups on the benefits of smart appliances.

Respondents were found to be sensitive to an availability of subsidies for the smart appliances, particularly among less flexible groups, suggesting that either they may perceive such appliances as being too expensive or they may be more sensitive to prices. Uptake of such DR programs among less flexible groups may thus be maximised by offering financial incentives, or by explaining the potential for such programs to lead to financial benefits for the users.

Lastly, age was found to have an inverse relationship with the potential for demand flexibility among more responsive groups, possibly because younger participants were more comfortable with technology, more aware of environmental issues, or more likely to have a smaller family. Thus, while younger respondents may represent low-hanging fruit to realise some of the benefits of DR, in the longer term, more effort should be invested into getting older segments involved in such programs. Among less responsive groups, age was not as significant of a factor, suggesting that these segments may have other concerns that might be better addressed by the steps outlined above.

In this way, the overall analysis complemented findings from existing research and then uncovered some of the complexities hidden in these general findings. However, the results in this paper are drawn from a limited sample of 155 families in Flanders, Belgium. Further, the Linear trial project did not start from an assessment of the needs and motivations of end users; rather, stakeholders were mainly interested in how to get 'flexibility' from end users. Future research should look at a broader and more representative sample ${ }^{11}$ with greater focus on how to build customer engagement and reduce resistance to participating in DR, by looking at the concerns of each segment of the target population.

For now, Denmark and Germany are leading on projects focusing on consumer engagement in Europe [43]. In the US, consumer behaviour studies are examining customer participation in DR, and the influence of enabling technologies on customer response [44,45]. Building on this current study, a deeper look into the relationships between customer response and perceptions, in a broader range of regions, would greatly help with the implementation of the EU Clean Energy package and the ensured security of energy supply.

\footnotetext{
${ }^{11}$ Keeping in mind however that rollouts often proceed in a phased manner, with an initial focus on early adopters such as those who participated in the Linear project.
} 


\section{Declarations of interest}

None.

\section{Funding}

This research did not receive any specific grant from funding agencies in the public, commercial, or not-for-profit sectors.

\section{Acknowledgements}

This work continued on the results and data of the project Linear that was supported by the Flemish Ministry of Science and organised by the Institute for Science and Technology (IWT). The authors gratefully acknowledge the support extended by Wim Cardinaels at VITO in helping them access the underlying Linear data.

\section{Appendix A. Predictor Variables}

The 40 predictor variables that were used in the analysis - and were drawn mainly from the surveys - are listed in Table A1 below.

Table A1

Predictor Variables.

\begin{tabular}{|c|c|}
\hline Question & Variable Type \\
\hline Gender & Nominal \\
\hline Age & Continuous \\
\hline During the field test, Linear showed variable rates. To what extent did you take these rates into account when using the devices? & Ordinal \\
\hline Were there certain household routines or habits that restricted flexibility? & Nominal \\
\hline During Linear you had a tablet available. Was the information you received through the tablet about your energy consumption sufficient? & Nominal \\
\hline Was the information from the device/controller displays sufficient? & Nominal \\
\hline How frequently did you check your smart meter? & Ordinal \\
\hline Is the following information easy to read from the smart meter display? - Current consumption & Nominal \\
\hline Is the following information easy to read from the smart meter display? - Rate type & Nominal \\
\hline Do you believe that you consumed less thanks to this smart meter in your home? & Nominal \\
\hline Were you worried when using your appliances about your privacy? & Ordinal \\
\hline Did you experience a loss in comfort by participating in Linear? & Ordinal \\
\hline To what extent do you agree with the following statements: Our behaviour changed as the field test progressed & Ordinal \\
\hline To what extent do you agree with the following statements I would have liked more information about when the flexibility that I give is used & Ordinal \\
\hline To what extent do you agree with the following statements: The use of smart appliances seems to have no benefits & Ordinal \\
\hline To what extent do you agree with the following statements: Smart appliances are easy to work with & Ordinal \\
\hline To what extent do you agree with the following statements: The use of smart appliances makes me work more efficiently & Ordinal \\
\hline To what extent do you agree with the following statements: I use the various features of smart appliances & Ordinal \\
\hline To what extent do you agree with the following statements: I made use of my smart appliances & Ordinal \\
\hline To what extent do you agree with the following statements: I questioned the safety of smart appliances (eg risk of fire) & Ordinal \\
\hline To what extent do you agree with the following statements: I think smart appliances allow too little control to the user & Ordinal \\
\hline To what extent do you agree with the following statements: I doubt these smart appliances will be more environmentally friendly & Ordinal \\
\hline What factors might play a role in deciding to buy smart appliances or an energy management system? - Environmental considerations & Ordinal \\
\hline What factors might play a role in deciding to buy smart appliances or an energy management system? - Savings $(€)$ & Ordinal \\
\hline What factors might play a role in deciding to buy smart appliances or an energy management system? - Subsidies & Ordinal \\
\hline What factors might play a role in deciding to buy smart appliances or an energy management system? - Ability to operate appliances remotely & Ordinal \\
\hline What factors might play a role in deciding to buy smart appliances or an energy management system? - Experimenting with new technology & Ordinal \\
\hline What factors might play a role in deciding to buy smart appliances or an energy management system? - Greater stability of energy supply & Ordinal \\
\hline Mean scores on Safety & Ordinal \\
\hline Mean scores on Comfort & Ordinal \\
\hline Mean scores on Control & Ordinal \\
\hline Mean scores on Cost & Ordinal \\
\hline Mean scores on Privacy & Ordinal \\
\hline I can generally work with high-tech products & Ordinal \\
\hline New technology is often too complex to be useful & Ordinal \\
\hline Technology gives people more control over their daily lives & Ordinal \\
\hline Technology makes me more efficient in my work & Ordinal \\
\hline Changes to mean scores on attitude & Ordinal \\
\hline Total installed PV power (kWp) & Continuous \\
\hline Mean scores on Perceived environment friendliness & Ordinal \\
\hline
\end{tabular}

\section{Appendix B. Diagnostics for Model OLS Regression}

Diagnostic plots for the OLS regression, for the model captured in Eq. (5), are provided in Fig. B1 below.

These plots show that the residuals decrease as the fitted values increase, that the data is right-skewed, and that the variance might not be equal, although there are no influential cases that fall outside of Cook's distance lines. Overall, the data is not normally distributed or homoscedastic.

Chi-squared tests of correlations among the categorical variables summarized in Table 2 show correlations between questions 2 (SA_NBenefits) and 4 (Used_SA), and between questions 3 (SA_Efficient) and 4 (Used_SA). However, a check for multicollinearity among the variables in Table 2 yields the generalised variance inflation factors (GVIFs) outlined in Table B1 below. The low values indicate that collinearity is not a problem in this model. 


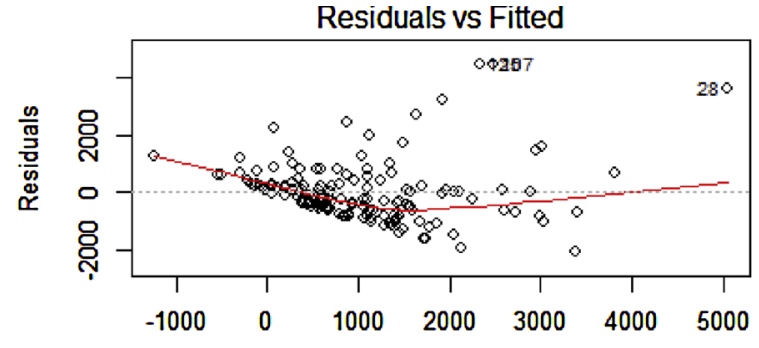

Fitted values

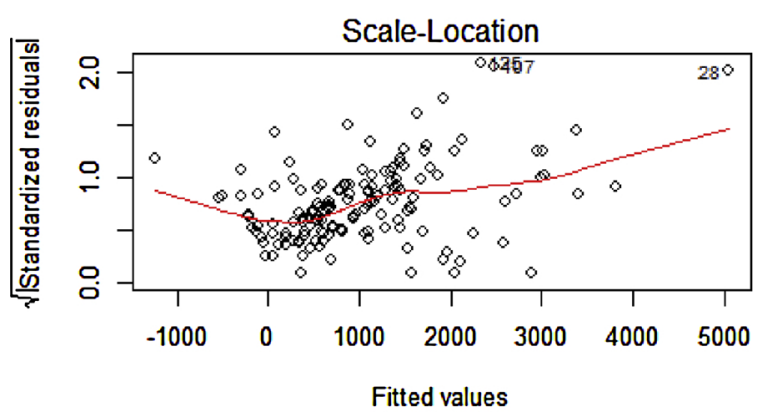

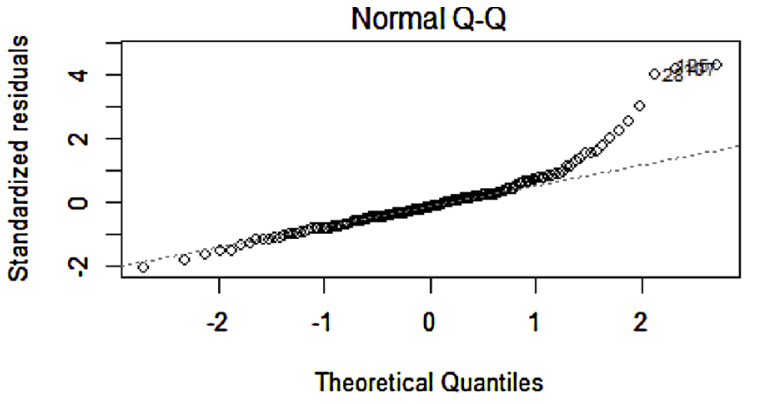

Residuals vs Leverage

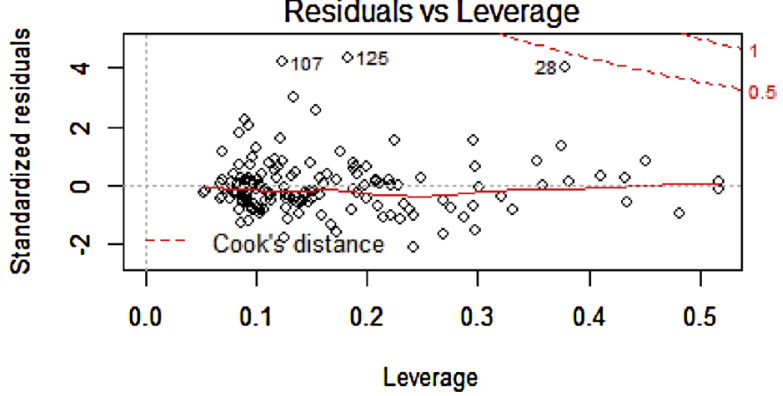

Fig. B1. [a-d]: OLS Diagnostic Plots.

Table B1

Test for Multicollinearity.

\begin{tabular}{llll}
\hline Ques & GVIF & Df & GVIF $^{\wedge}\left(1 /\left(2^{*} \mathrm{Df}\right)\right)$ \\
\hline 1 & 1.379 & 1 & 1.174 \\
2 & 2.340 & 4 & 1.112 \\
3 & 2.773 & 4 & 1.136 \\
4 & 2.614 & 3 & 1.173 \\
5 & 2.034 & 4 & 1.092 \\
6 & 1.721 & 4 & 1.070 \\
7 & 1.970 & 4 & 1.088 \\
\hline
\end{tabular}

\section{References}

[1] US Environmental Protection Agency, Inventory of US Greenhouse Gas Emissions and Sinks, 1990-2016, EPA, 2018, https://www.epa.gov/sites/production/files/ 2018-01/documents/2018 complete report.pdf.

[2] Elia, The Primary Reserve: A Solution for Stabilizing the Frequency in the European Interconnected System, Elia, 2008 http://www.elia.be/ /media/files/Elia/ Products-and-services/ProductSheets/S-Ondersteuning-net/ S1_F RES PRIMAIRE.pdf.

[3] Elia, Ancillary Services (Accessed 03 July 2018), http://www.elia.be/en/productsand-services/ancillary-services.

[4] Restore, Belgian TSO Elia in Demand Response First (Accessed 05 August 2018), https://restore.energy/export/pdfNews/113.

[5] World Energy Council, E-Storage: Shifting From Cost to Value -Wind and Solar Applications, World Energy Council, 2016, https://www.worldenergy.org/wpcontent/uploads/2016/03/Resources-E-storage-report-2016.02.04.pdf.

[6] Eurelectric, Dynamic Pricing in Electricity Supply, Eurelectric, 2017, http://www. elecpor.pt/pdf/16_02_2017_Dynamic_pricing_in_electricity_supply.pdf.

[7] H.C. Gils, Assessment of the theoretical demand response potentnial in Europe, Energy 67 (2014) 1-18, https://doi.org/10.1016/j.energy.2014.02.019.

[8] European Commission, Commission Proposes New Rules for Consumer Centered Clean Energy Transition (Accessed 28 April 2018), https://ec.europa.eu/energy/ en/news/commission-proposes-new-rules-consumer-centred-clean-energytransition.

[9] Joint Research Center, Smart Grid Projects Map (Accessed 18 March 2018), http:// ses.jrc.ec.europa.eu/sites/ses.jrc.ec.europa.eu/files/u24/2014/project_maps_28 april_2014.html.

[10] US Department of Energy, Smart Grid Demonstration Program (Accessed 18 March 2018), https://www.smartgrid.gov/recovery_act/overview/smart_grid_ demonstration program.html.

[11] SEDC, Explicit Demand Response in Europe - Mapping the Markets 2017, SEDC, 2017, http://www.smartenergydemand.eu/wp-content/uploads/2017/04/SEDCExplicit-Demand-Response-in-Europe-Mapping-the-Markets-2017.pdf.

[12] S. Gyamfi, S. Krumdieck, T. Urmee, Residential peak electricity demand response-highlights of some behavioural issues, Renew. Sustain. Energy Rev. 25 (2013) 71-77, https://doi.org/10.1016/j.rser.2013.04.006.

[13] C. Bartusch, F. Wallin, M. Odlare, I. Vassileva, L. Wester, Introducing a demandbased electricity distribution tariff in the residential sector: demand response and customer perception, Energy Policy 39 (9) (2011) 5008-5025, https://doi.org/10. 1016/j.enpol.2011.06.013.

[14] N.L. Hall, T.D. Jeanneret, A. Rai, Cost-reflective electricity pricing: consumer preferences and perceptions, Energy Policy 95 (2016) 62-72, https://doi.org/10.1016/ j.enpol.2016.04.042.

[15] M. Muratori, B.A. Schuelke-Leech, G. Rizzoni, Role of residential demand response in modern electricity markets, Renew. Sustain. Energy Rev. 33 (2014) 546-553, https://doi.org/10.1016/j.rser.2014.02.027.

[16] S.J. Darby, E. McKenna, Social implications of residential demand response in cool temperate climates, Energy Policy 49 (2012) 759-769, https://doi.org/10.1016/j. enpol.2012.07.026.

[17] Y. Parag, G. Butbul, Flexiwatts and seamless technology: public perceptions of demand flexibility through smart home technology, Energy Res. Soc. Sci. 39 (2018) 177-191, https://doi.org/10.1016/j.erss.2017.10.012.

[18] W. Mert, Consumer Acceptance of Smart Appliances, European Commission, 2008, https://ec.europa.eu/energy/intelligent/projects/sites/iee-projects/files/projects/ documents/e-track_ii_consumer_acceptance.pdf.

[19] D.A. Brent, L. Friesen, L. Gangadharan, A. Leibbrandt, Behavioral Insights from Field Experiments in Environmental Economics, discussion paper 34/16 Monash Business School, 2016, http://business.monash.edu/ data/assets/pdf file/0005/ 588785/3416behavioralbrentfriesengangadharanliebbrandt.pdf.

[20] US Department of Energy, Consumer Behavior Studies (Accessed 27 July 2018), https://www.smartgrid.gov/recovery_act/overview/consumer_behavior_studies. html.

[21] K. Kessels, C. Kraan, L. Karg, S. Maggiore, P. Valkering, E. Laes, Fostering residential demand response through dynamic pricing schemes: a behavioural review of smart grid pilots in Europe, Sustainability 8 (9) (2016) 929 http://www.mdpi. com/2071-1050/8/9/929.

[22] M. Vesterberg, The hourly income elasticity of electricity, Energy Econ. 59 (2016) 188-197, https://doi org/10.1016/j eneco.2016.08.014.

[23] S. Silva, I. Soares, C. Pinho, Electricity demand response to price changes: the 
Portuguese case taking into account income differences, Energy Econ. 65 (2017) 335-342, https://doi.org/10.1016/j.eneco.2017.05.018.

[24] Irish Commission for Energy Regulation, Electricity Smart Metering Customer Behavior Trials Findings Report, CER, 2011, http://www.cer.ie/docs/000340/ cer11080(a)(i).pdf.

[25] V. Di Cosmo, D. O'Hora, Nudging electricity consumption using TOU pricing and feedback: evidence from Irish households, J. Econ. Psychol. 61 (2017) 1-14, https://doi.org/10.1016/j.joep.2017.03.005.

[26] B. Parrish, R. Gross, P. Heptonstall, On demand: can demand response live up to expectations in managing electricity systems? Energy Res. Soc. Sci. 51 (2019) 107-118, https://doi.org/10.1016/j.erss.2018.11.018.

[27] A. Srivastava, S. Van Passel, E. Laes, Assessing the success of electricity demand response programs: a meta-analysis, Energy Res. Soc. Sci. 40 (2018) 110-117, https://doi.org/10.1016/j.erss.2017.12.005.

[28] P. Bertoldi, P. Zancanella, B. Boza-Kiss, Demand Response Status in EU Member States, JRC Science for Policy, 2016, http://publications.jrc.ec.europa.eu/ repository/bitstream/JRC101191/ldna27998enn.pdf.

[29] Elia, Adequacy Study for Belgium: The Need for Strategic Reserve for Winter 2018-19 (Accessed 07 June 2018), http://www.elia.be/en/about-elia/newsroom/ news/2017/20171130 Strategic-reserve-for-winter-2018-19.

[30] Linear, Home Page (Accessed 15 July 2018), www.linear-smartgrid.be.

[31] N. Kaza, Understanding the spectrum of residential energy consumption: a quantile regression approach, Energy Policy 38 (11) (2010) 6574-6585, https://doi.org/10. 1016/j.enpol.2010.06.028.

[32] N.Z. Khanna, J. Guo, X. Zheng, Effects of demand side management on Chinese household electricity consumption: empirical findings from Chinese household survey, Energy Policy 95 (2016) 113-125, https://doi.org/10.1016/j.enpol.2016. 04.049 .

[33] D. Romero-Jordán, P. del Río, C. Peñasco, An analysis of the welfare and distributive implications of factors influencing household electricity consumption, Energy Policy 88 (2016) 361-370, https://doi.org/10.1016/j.enpol.2015.09.037.

[34] The Linear Consortium, Linear: The Report, Linear, 2014, http://www.linearsmartgrid.be/sites/default/files/boekje_linear_okt_2014_boekje_web.pdf.

[35] Statbel, An Overview of Belgian Wages and Salaries (Accessed 20 August 2018), https://statbel.fgov.be/en/themes/work-training/overview-belgian-wages-and- salaries.

[36] M. Broman Toft, G. Schuitema, J. Thøgersen, Responsible technology acceptance: model development and application to consumer acceptance of Smart Grid technology, Appl. Energy 134 (2014) 392-400, https://doi.org/10.1016/j.apenergy. 2014.08.048.

[37] L. Hao, D. Naiman, Quantile regresssion, Quantile Regression, (2007), pp. 1-6, https://doi.org/10.1002/9780470057339.vnn091.

[38] I. Takeuchi, Q.V. Le, T. Sears, A.J. Smola, Nonparametric quantile regression, J. Mach. Learn. Res. 7 (2005) 1001-1032, https://doi.org/10.1080/ 10485259508832642.

[39] R. Koenker, A note on studentizing a test for heteroscedasticity, J. Econom. 17 (1) (1981) 107-112, https://doi.org/10.1016/0304-4076(81)90062-2.

[40] R. Koenker, J.A.F. Machado, Goodness of fit and related inference processes for quantile regression, J. Am. Stat. Assoc. 94 (448) (1999) 1296-1310, https://doi. org/10.1080/01621459.1999.10473882.

[41] N. Hauk, J. Hüffmeier, S. Krumm, Ready to be a silver surfer? A meta-analysis on the relationship between chronological age and technology acceptance, Comput. Hum. Behav. 84 (2018) 304-319, https://doi.org/10.1016/j.chb.2018.01.020.

[42] C.B.A. Kobus, E.A.M. Klaassen, R. Mugge, J.P.L. Schoormans, A real-life assessment on the effect of smart appliances for shifting households' electricity demand, Appl. Energy 147 (2015) 335-343, https://doi.org/10.1016/j.apenergy.2015.01.073.

[43] V. Giordano, A. Meletiou, C.F. Covrig, A. Mengolini, M. Ardelean, G. Fulli, M.S. Jimenez, C. Filiou, Smart Grid Projects in Europe: Lessons Learned and Current Developments, JRC Science and Policy, 2013, https://ses.jrc.ec.europa.eu/sites/ses. jrc.ec.europa.eu/files/publications/ld-na-25815-en-n_final_online_version_april_15_ smart_grid_projects_in_europe_-_lessons_learned_and_current_developments_-2012 update.pdf.

[44] US Department of Energy, Demand Response - Policy (Accessed 18 August 2018), https://www.energy.gov/oe/services/electricity-policy-coordination-andimplementation/state-and-regional-policy-assistanc-4.

[45] US Department of Energy, Interim Report on Customer Acceptance, Retention, and Response to Time-Based Rates from the Consumer Behavior Studies, US Department of Energy, 2015, https://www.energy.gov/sites/prod/files/2015/06/f24/ARRACBS_interim_program_impact_report_June2015.pdf. 